\title{
Workforce Participation Barriers for People With Disability
}

\author{
Anthony Hogan, ${ }^{1}$ Su Mon Kyaw-Myint, ${ }^{2}$ Debra Harris, ${ }^{2}$ and Harmony Denronden ${ }^{1}$ \\ ${ }^{1}$ School of Sociology, Australian National University, Australia \\ ${ }^{2}$ National Centre for Epidemiology and Population Health, Australian National University, Australia
}

\begin{abstract}
A ccess to meaningful and equitably paid work is an ongoing issue facing people with disabilities across the world. This article is concerned with the nature and extent of workplace accommodation currently made available in Australia to people with disabilities. The article is based on analysis of the Australian Survey of Disability Ageing and Carers (2003). The article first ratifies existing findings in the literature that people with disability are less likely to be employed and where employed, are likely to be underemployed and underpaid. Restrictions in the ability to participate in paid work without accommodations were common with the need for accommodation varying from $43 \%$ through to $91 \%$, depending on the nature of disability experienced. We identify the possibility that people with disability self-select themselves into workplaces where they can self-accommodate their own access needs. Generally, the extent of workplace accommodations provided were low $(12 \%-27 \%)$. Known stratifying factors (gender, ethnicity, and education) exacerbated existing barriers to accessing employment. Workers with higher training needs were less likely to secure employment while people accessing the workplace with the benefit of an advocate were more likely to be in the workforce. Strategies for enhancing employment outcomes are discussed.
\end{abstract}

Keywords: disability, employment, workplace accommodation, employment restrictions

People with disability represent a significant proportion of any country's population and potential workforce. In developed nations people with disability constitute between 14\% and 20\% of the population (Organisation for Economic Co-operation and Development [OECD], 2003). Evidence suggests that people with disability are much less likely to be in the labour force compared to nondisabled people in the western world. Previous studies in the United Kingdom (UK) and United States (US) have found labour force participation rates for people with disability are less than half the rate of participation for those without disability (Hale, Hayghe, \& McNeil, 1998; Jones \& Latreille, 2007; Kidd, Sloane, \& Ferko, 2000; Roulstone \& Warren, 2006). Significant literature highlights the fact that unemployment is detrimental to wellbeing, as is evidenced through reduced access to financial resources and decreased ability to meet psychological needs such as meaningful activity and social contact (Creed \& Muller, 2006; Creed, Muller, \& Machin, 2001; Fryer, 1986; Jahoda, 1982; Paul, Geithner, \& Moser, 2009), with additional studies linking unemployment to both poor physical (Broom et al., 2006) and mental health (Murphy \& Athanasou, 1999; Turner \& Turner, 2004). People with disability earn significantly less compared to those without disability (Jones, 2008), and experience more underemployment. They are overrepresented in manual occupations and underrepresented in 'white collar' jobs (Kidd et al., 2000), and are more likely to be working in nonstandard forms of employment, such as part-time and temporary jobs (Jones, 2008).

In many western countries legislation is in place (e.g., in Australia, the Disability Discrimination Act [DDA]; Office of Legislative Drafting and Publishing, 2006), which aims to ensure that people with disability have access to the same employment opportunities as those without disabilities, and hence also the range of benefits associated with working. Such benefits include job satisfaction, job tenure, productivity, and personal achievements (Ellingsen \& Aas, 2009; Fabian, Waterworth, \& Ripke, 1993; Fesko, 2001; Murphy \& Young, 2006; Rumrill, Roessler, Battersby-Longden, \& Schuyler, 1998). To these ends such legislation requires that 'reasonable adjustments' (otherwise referred

Address for correspondence: Anthony Hogan PhD, Fellow, School of Sociology, Room 2156, Haydon Allen Building, Australian National University, Canberra NSW 0200, Australia. E-mail: anthony.hogan@anu.edu.au 
to as reasonable accommodations) are made by workplaces to ensure that people with disability, who possess the necessary skills for a particular role, have an equal opportunity to perform that role as able-bodied people.

While a range of assistive technologies and workplace accommodations are available for workers with a variety of disabilities (for a review, see Butterfield \& Ramsuer, 2004), the literature on the extent to which workers with disability have access to reasonable accommodation is quite small (see, e.g., Butterfield \& Ramseur, 2004; Murphy \& Young, 2006). Additionally, many studies focus on just one or a select few disabilities, making it difficult to gain a broad picture of the systematic provisions of accommodations across people and workplaces. In one of the few US studies that examined workplace accommodations for those with a wide range of physical and psychological disabilities, Zwerling and colleagues (2003) found that of the small proportion $(16 \%)$ of people reporting the need for an accommodation from their employer, approximately three quarters received it. However, more recent US research has found that people with disability do not believe their industry is proactive in hiring them (Lengnick-Hall, Gaunt, \& Kulkarni, 2008). In the UK, progress with regard to workplace accommodations is modest (Meager et al., 2002) and in Australia, the evidence is sparse, with little known about the prevalence or distribution of workplace accommodations by occupation, disability type, or other characteristics. One qualitative study found that any workplace accommodations made by people with severe hearing loss were primarily undertaken by the individuals themselves and predominantly managed on the basis of their own personality, while vocational rehabilitation support was absent (Hogan, Stewart, \& Giles, 2002). That is, to be successfully employed, workers had to accommodate themselves to the workplace. This study is concerned with examining the nature and extent of workplace accommodations currently made in Australia for people with disability, with regard to how such accommodations might differ according to disability characteristics.

\section{Method}

Analysis was undertaken using data from the most recently available household component of the Confidentialised Unit Record File (CURF) of the Australian Bureau of Statistics (ABS) 2003 Survey of Disability, Ageing and Carers (SDAC; ABS, 2005). Data collection for this survey was conducted nationally across all states and territories throughout Australia between June and November 2003 using stratified random sampling $(n=41233)$. Within SDAC, disability is defined as a limitation, restriction, or impairment that has lasted, or is likely to last, for at least six months and restricts everyday activities. SDAC provided for a wide range of experiences of disability, taking into account psycho- logical, physiological, or anatomical aspects including physical, sensory, and intellectual disabilities as well as mental illness. Using weighted data, $80 \%$ reported no disability, $8 \%$ reported having one disability, and $12 \%$ reported having two or more type of disability. Severity of disability is classified based on limitations or restrictions in core activities, which include self-care (such as bathing, eating, and toileting), mobility (including moving around home and other environments, using public transport), and communication (understanding and being understood by others) (ABS, 2005).

Within the dataset, individuals with disability were classified as having employment restrictions if their disability restricts the type of job they can do, the number of hours they can work, and/or makes it difficult to change or get a preferred job, or if they need employerprovided special arrangements or equipment, a support person at work, ongoing supervision or assistance, or are permanently unable to work. The nature of workplace accommodations included the presence of any special employer arrangements provided to employees, such as provision of special equipment or training, modification of equipment/buildings, or allocation of different duties.

An employment income variable was created from the original SDAC data to enable income comparisons between people with and without disability in paid work. CURF data for total weekly gross personal income from wages or salary was utilised; any additional income from pensions or benefits was not included. Weekly gross income is categorised into 10 groups, from $\$ 129$ or less, to the highest at $\$ 1151$ and over. The median gross income in 2003-04 from wages and salary was $\$ 577$, with the nearest income category to the median income being $\$ 460-\$ 574$. Based on these data, a new binary variable for income was created, converting income data into two groups: (a) those earning either the median income or less, and (b) those earning above the median income level.

\section{Analyses}

This study was concerned to identify factors that influenced the labour force participation of people with disability, with particular attention placed on the extent to which people with disability seeking employment were able to access workplace accommodations. A three-step analytical process was undertaken to address this research goal. First, descriptive analysis was undertaken to examine employment outcomes for people with disability versus the rest of the workforce. This analysis was supplemented by a descriptive examination of other factors (e.g., education, sex and age) known to impact on employment outcomes. These analyses revealed a considerable number of differences between people with disability and other workers with regards workforce enabling factors and participation outcomes 
such that some may be statistically significant by chance alone. To this end, backward logistic regression was employed to identify which factors uniquely contribute to employment outcomes for people with disability, taking into account the associations which may exist between variables possibly contributing to the outcome. Backward logistic regression reduced the risk of failing to find a statistically significant relationship when one exists (Menard, 2002).

Analysis was conducted at the individual level, as well as using weighted scores developed by the ABS (2005) to infer results for the total population. This was done to generate national estimates from the results of this study. Analyses conducted on the weighted and nonweighted data produced similar results. Initially, labour force participation rates were compared across disability status, followed by an exploration of occupation and industry type comparing those with and without disability. To identify which components of these cross-tabulations contributed to a statistically significant finding, if any, an analysis was conducted of the adjusted residuals within the cross-tabulation, in this case by occupation or industry of employment by disability status. Adjusted residuals above $+/-2$ are considered to be statistically important (Hogan, Shipley, Strazdins, Purcell, \& Baker, 2011). Descriptive analyses were also performed to examine factors that may contribute to differences in employment outcome between those with and without disability, including earnings and level of education. These analyses provide the necessary context for considering the study's overall research question. Backward logistic regression analyses were undertaken to examine the dependent variables contributing to employment outcome, taking into account workplace accommodations.

\section{Results}

\section{Comparison of Employment Characteristics by Disability Status}

Table 1 shows that the labour force participation rate for people with disability was much lower than those with no reported disability, with $59 \%$ of males and $47 \%$ of females with disability in the labour force, compared to $89 \%$ of males and $72 \%$ of females without disability. The labour force participation rate for people with no disability in the SDAC dataset is slightly higher than that of the general Australian population in 2003 (81\% vs. 75\%; ABS, 2010).

Among individuals in the labour force, the two most common occupation types regardless of disability status were Professionals, followed by Intermediate Clerical, Sales and Service Workers (see Table 2). Additional analysis indicated significant differences by disability status for three occupations. A significantly larger proportion of people with no disability were Associate Professionals compared to people with disability, while people with
TABLE 1

Labour Force Status by Disability Status and Gender for Persons 15-64 Years of Age

\begin{tabular}{|c|c|c|c|c|}
\hline & \multicolumn{2}{|c|}{$\begin{array}{l}\text { Has disability } \\
\text { (\% within sex) }\end{array}$} & \multicolumn{2}{|c|}{$\begin{array}{l}\text { No disability } \\
\text { (\% within sex) }\end{array}$} \\
\hline & Males & Females & Males & Females \\
\hline Employed working full-time & 41.8 & 19.6 & 71.9 & 36.6 \\
\hline Employed working part-time & 12.4 & 23.6 & 12.8 & 31.9 \\
\hline $\begin{array}{l}\text { Unemployed looking for } \\
\text { full-time work }\end{array}$ & 3.9 & 1.8 & 3.4 & 1.9 \\
\hline $\begin{array}{l}\text { Unemployed looking for } \\
\text { part-time work }\end{array}$ & 1.3 & 2.1 & 0.9 & 1.9 \\
\hline Not in the labour force & 40.7 & 53.0 & 11.0 & 27.0 \\
\hline $\begin{array}{l}\text { Labour force participation } \\
\text { rate }\end{array}$ & 59.3 & 47.0 & 89.0 & 73.0 \\
\hline Total & 100 & 100 & 100 & 100 \\
\hline
\end{tabular}

disability were significantly more likely than those without disability to be employed as Intermediate Production and Transport Workers, and Labourers and Related Workers.

As shown in Table 3, in terms of industry of employment, people with disability were most commonly working in Retail Trade, Manufacturing, and Health and Community Services. In contrast, those without a disability were most commonly employed in Retail Trade, followed by Property and Business Services, and

\section{TABLE 2}

Occupation Type for 15-64 Year Olds Who Were in the Labour Force by Disability Status

\begin{tabular}{|c|c|c|c|c|}
\hline & \multicolumn{2}{|c|}{ No disability ${ }^{a}$} & \multicolumn{2}{|c|}{ Has disability ${ }^{a}$} \\
\hline & $N$ & $\%$ & $N$ & $\%$ \\
\hline $\begin{array}{l}\text { Managers and } \\
\text { administrators }\end{array}$ & 694,799 & 8.1 & 91,208 & 8.4 \\
\hline Professionals & $1,641,945$ & 19.2 & 199,207 & 18.4 \\
\hline Associate professionals & $1,138,254$ & $13.3^{*}$ & 103,834 & $9.6^{*}$ \\
\hline $\begin{array}{l}\text { Tradespersons and related } \\
\text { workers }\end{array}$ & $1,092,473$ & 12.8 & 128,092 & 11.8 \\
\hline $\begin{array}{l}\text { Advanced clerical and } \\
\text { service workers }\end{array}$ & 337,827 & 4.0 & 47,925 & 4.4 \\
\hline $\begin{array}{l}\text { Intermediate clerical, sales } \\
\text { and service workers }\end{array}$ & $1,461,427$ & 17.1 & 176,618 & 16.3 \\
\hline $\begin{array}{l}\text { Intermediate production and } \\
\text { transport workers }\end{array}$ & 658,416 & $7.7^{*}$ & 114,658 & $10.6^{*}$ \\
\hline $\begin{array}{l}\text { Elementary clerical, sales } \\
\text { and service workers }\end{array}$ & 831,330 & 9.7 & 102,500 & 9.5 \\
\hline $\begin{array}{l}\text { Labourers and related } \\
\text { workers }\end{array}$ & 668,228 & $7.8^{*}$ & 118,044 & $10.9^{*}$ \\
\hline Inadequately described & 5,471 & 0.1 & 662 & 0.1 \\
\hline
\end{tabular}

Note: $\chi^{2}(9, N=17,203)=57.225, p<.001,{ }^{*}$ statistical significant difference by disability status with adjusted residuals above $+/-2$, aexcluding not applicable responses. 


\section{TABLE 3}

Industry of Employment for 15-64 Year Olds Who Were in the Labour Force by Disability Status

\begin{tabular}{|c|c|c|c|c|}
\hline & \multicolumn{2}{|c|}{ No disability ${ }^{a}$} & \multicolumn{2}{|c|}{ Has disabilitya } \\
\hline & $N$ & $\%$ & $N$ & $\%$ \\
\hline $\begin{array}{l}\text { Agriculture, forestry and } \\
\text { fishing }\end{array}$ & 309,623 & $3.6^{*}$ & 57,108 & $5.3^{*}$ \\
\hline Mining & 81,035 & 0.9 & 14,724 & 1.4 \\
\hline Manufacturing & 959,795 & 11.3 & 123,628 & 11.4 \\
\hline $\begin{array}{l}\text { Electricity, gas and water } \\
\text { supply }\end{array}$ & 68,753 & 0.8 & 6,297 & 0.6 \\
\hline Construction & 720,407 & 8.4 & 97,338 & 9.0 \\
\hline Wholesale trade & 397,310 & 4.7 & 45,748 & 4.2 \\
\hline Retail trade & $1,242,026$ & $14.6^{*}$ & 129,467 & $12.0^{*}$ \\
\hline $\begin{array}{l}\text { Accommodation, cafes and } \\
\text { restaurants }\end{array}$ & 449,460 & $5.3^{*}$ & 40,823 & $3.8^{*}$ \\
\hline Transport and storage & 352,483 & 4.1 & 55,077 & 5.1 \\
\hline Communication services & 161,176 & 1.9 & 15,554 & 1.4 \\
\hline Finance and insurance & 334,844 & $3.9^{*}$ & 25,393 & $2.3^{*}$ \\
\hline $\begin{array}{l}\text { Property and business } \\
\text { services }\end{array}$ & $1,034,547$ & 12.1 & 112,988 & 10.4 \\
\hline $\begin{array}{l}\text { Government administration } \\
\text { and defence }\end{array}$ & 437,314 & 5.1 & 63,088 & 5.8 \\
\hline Education & 607,644 & 7.1 & 94,305 & 8.7 \\
\hline $\begin{array}{l}\text { Health and community } \\
\text { services }\end{array}$ & 821,937 & 9.6 & 116,103 & 10.7 \\
\hline $\begin{array}{l}\text { Cultural and recreation } \\
\text { services }\end{array}$ & 208,081 & 2.4 & 25,130 & 2.3 \\
\hline Personal and other services & 343,733 & $4.0^{*}$ & 59,976 & $5.5^{*}$ \\
\hline
\end{tabular}

Note: $\chi^{2}(16, N=17,203)=65.567, p<.001$, "statistical significant difference by disability status with adjusted residuals above $+/-2$,

a excluding not applicable responses.

Manufacturing. A significant difference was observed for the proportion of people employed in Agriculture, Forestry and Fishing by disability status, with those with disability significantly more likely to be employed in this industry.

\section{Effect of Education on Labour Force Participation and Income}

Despite having the same level of educational qualifications, a smaller proportion of people with disability were in the labour force compared to those without a disability. In particular, $71 \%$ of people with disability holding a bachelor degree were in the labour force, approximately $20 \%$ lower than the comparative figure for people without a disability (90\%).

Overall, $22 \%$ of people with disability were in the 'above median income group' (earning $>\$ 574$ a week) compared to $47 \%$ of people with no disability. These data were further analysed in terms of educational qualifications, showing that even when level of educational qualification was comparable, a smaller proportion of people with disability were earning above the median income, compared to people without disability. For instance, among those with postgraduate qualifications, $82 \%$ of people without disability earned above median income compared to $74 \%$ of people with disability. This pattern was demonstrated across all levels of education.

\section{Factors Contributing to Labour Force Participation of People With Disability}

Given the observed differences in the level of labour force participation by disability status, the data were further examined to determine the specific factors influencing labour force participation of people with disability.

Overall, for people with disability, the proportion in the labour force increased with higher educational qualifications, indicating that education has a positive effect on labour force participation. Labour force participation rates also differed according to severity of disability: those with lower levels of disability severity had a higher rate of participation in the labour force (see Table 4). Among people with disability with no restrictions or limitations in core activities, $80 \%$ were in the labour force, compared to just $15 \%$ of people with profound core activities limitation.

\section{TABLE 4}

Labour Force Participation Status for 15-64 Year Olds with Disability by Core Activity Limitation (\%)

\begin{tabular}{|c|c|c|c|c|c|}
\hline & $\begin{array}{l}\text { Working } \\
\text { full-time }\end{array}$ & $\begin{array}{l}\text { Working } \\
\text { part-time }\end{array}$ & $\begin{array}{l}\text { Unemployed } \\
\text { looking for } \\
\text { full-time work }\end{array}$ & $\begin{array}{l}\text { Unemployed } \\
\text { looking for } \\
\text { part-time work }\end{array}$ & $\begin{array}{c}\text { Not in } \\
\text { the labour } \\
\text { force }\end{array}$ \\
\hline Profound core activities limitation & 6.6 & 6.5 & 0.0 & 2.1 & 84.8 \\
\hline Severe core activities limitation & 16.7 & 15.9 & 2.5 & 0.9 & 64.0 \\
\hline Moderate core activities limitation & 27.1 & 17.2 & 2.2 & 1.4 & 52.0 \\
\hline Mild core activities limitation & 29.1 & 17.6 & 2.8 & 1.1 & 49.4 \\
\hline Not limited in core activities but restricted & 36.9 & 21.7 & 5.3 & 4.5 & 31.6 \\
\hline Not limited or restricted in core activities & 55.2 & 21.6 & 2.8 & 0.7 & 19.6 \\
\hline Total & 30.9 & 17.9 & 2.8 & 1.7 & 46.7 \\
\hline
\end{tabular}


TABLE 5

Labour Force Participation Rates for 15-64 Year Olds With Disability by Disability Type and Number of Co-Existing Impairments

\begin{tabular}{lccc}
\hline & & \multicolumn{3}{c}{ Labour force participation rate } \\
\cline { 2 - 4 } & 1 impairment & 2-5 impairments & $6-10$ impairments \\
\hline Mental illness & 36.2 & 30.7 & 8.8 \\
Nervous and emotional condition & 48.6 & 30.7 & 9.9 \\
Restrictions in physical activities or physical work & 63.1 & 38.7 & 14.4 \\
Slow at learning & 66.0 & 41.0 & 16.8 \\
Other disability types & 67.1 & 37.1 & 14.8 \\
Incomplete use of feet/legs & 67.4 & 44.7 & 14.2 \\
Speech difficulties & 69.8 & 45.3 & 22.3 \\
Breathing difficulties & 71.8 & 36.0 & 15.4 \\
Difficulty holding/gripping things & 72.0 & 42.0 & 16.7 \\
Blackouts & 72.7 & 42.9 & 5.1 \\
Chronic pain & 73.8 & 42.7 & 13.0 \\
Head injury/stroke/brain damage & 74.0 & 41.5 & 9.9 \\
Loss of hearing & 76.1 & 50.4 & 12.8 \\
Loss of sight & 76.9 & 38.2 & 17.1 \\
Disfigurement/deformity & 87.3 & 69.3 & 23.0 \\
Incomplete use of arms/fingers & 88.2 & 51.7 & 20.8 \\
\hline
\end{tabular}

For people with disability, labour force participation rates also varied according to the type of disability. As seen in Table 5, among people with only one type of impairment, individuals with a mental illness or a nervous and emotional condition reported the lowest overall labour force participation rates, while individuals with disfigurement and/or deformity or incomplete use of their arms and/or fingers reported the highest participation rates.

Additionally, lower labour force participation rates were also associated with the presence of multiple impairments, with labour force participation rates decreasing as the number of co-existing impairments increased. Controlling for age and gender, those with one impairment are 3.39 times more likely to be in the labour force compared to those with two or more impairments.

Backward logistic regression indicated that age, gender, educational level and country of birth (English vs. non-English speaking) had an impact on labour force participation of people with disability. Table 6 shows that the odds of being in the labour force declines with increasing age. People with disability who are male or from an English speaking country were more likely to be in the labour force compared to the reference group (female, non-English speaking country of origin). Those with a higher level of education were also more likely to be in the labour force compared to the reference group (Year 12 not completed).

\section{Employment Restrictions and Workplace Accommodations for People With Disability}

Table 7 presents the proportion of people with employment restrictions by type of disability. Employment restrictions include restrictions in type of work, hours of work, and the requirement for special equipment or a support person at work. Persons with mental illness $(91 \%)$ or nervous/emotional conditions $(88 \%)$ were most likely to report employment restrictions, while in contrast, less than half of people with blackouts or hearing loss reported experiencing employment restrictions.

Since not everyone with disability experiences work-related restrictions, a consideration of workplace adjustments to accommodate disabilities should

\section{TABLE 6}

Factors Influencing Labour Force Participation Adjusted for Age, Sex, Education and Country of Birth

\begin{tabular}{|c|c|}
\hline & Odds ratio $(95 \% \mathrm{Cl})$ \\
\hline \multicolumn{2}{|l|}{ Age $\left(60-64\right.$ years $\left.^{1}\right)$} \\
\hline $15-29$ years & $5.05(3.92-6.50)$ \\
\hline $30-39$ years & $5.21(4.05-6.70)$ \\
\hline $40-49$ years & $4.66(3.69-5.88)$ \\
\hline $50-59$ years & $2.74(2.19-3.42)$ \\
\hline \multicolumn{2}{|l|}{ Sex (female $\left.{ }^{1}\right)$} \\
\hline Male & $1.69(1.47-1.93)$ \\
\hline \multicolumn{2}{|c|}{ Education (Year 12 not completed ${ }^{1}$ ) } \\
\hline Postgraduate degree/diploma & $5.86(3.96-8.66)$ \\
\hline Bachelor degree & 4.39 (3.39-5.68) \\
\hline Diploma/certificate & $2.68(2.29-3.13)$ \\
\hline Year 12 completed & $2.19(1.76-2.74)$ \\
\hline \multicolumn{2}{|c|}{ Country of birth (non-English speaking ${ }^{1}$ ) } \\
\hline English speaking & $2.08(1.69-2.55)$ \\
\hline
\end{tabular}


TABLE 7

Employment Restrictions by Type of Disability for 15-64 Year Olds Who Were in the Labour Force by Disability Status

\begin{tabular}{lc}
\hline & $\begin{array}{c}\text { Percentage with } \\
\text { employment restriction }\end{array}$ \\
\hline Blackouts & 42.8 \\
Hearing loss & 45.7 \\
Vision loss & 57.9 \\
Speech difficulties & 63.8 \\
Difficulty holding/gripping things & 65.6 \\
Incomplete use of arms and fingers & 68.7 \\
Slow at learning & 68.9 \\
Breathing difficulties & 71.6 \\
Other & 73.8 \\
Head injury/stroke/other brain damage & 74.0 \\
Chronic pain & 78.1 \\
Incomplete use of feet/legs & 78.7 \\
Restriction in physical activities & 83.8 \\
Disfigurement/deformity & 84.7 \\
Nervous/emotional condition & 87.8 \\
Mental illness & 91.2 \\
\hline
\end{tabular}

concentrate first on people with disability who do report employment restrictions. Overall, when people with disabilities both in and out of the labour force reporting employment restrictions are included, only $12 \%$ were provided workplace accommodations by their employer. If the analysis is restricted to people with disability with employment restrictions who are in the labour force, the proportion provided with workplace accommodations was $27 \%$. Among people with disability who were 15 to 64 years old, about one in twenty $(5 \%)$ were provided with special equipment and $2.5 \%$ were allocated alternative duties to accommodate their disability (see Table 8).

Among different disability types, those with hearing loss and blackouts were least likely to have had a special arrangement made for them by their employer, with only $9 \%$ and $7 \%$ respectively reporting having received any such arrangement by their employer. People with mental illness were most likely to have been provided a workplace accommodation (56\%). The most common arrangement provided for employees with mental illness was a special support person to assist/train on the job, with $26 \%$ reporting assistance of this type.

Backward logistic regression analysis of factors related to labour force participation of those with disability was then repeated to include types of workplace accommodations (see Table 9). Respondents who were male, from an English speaking country, with a higher level of education were also more likely to be in the labour force than respondents who were female, migrants from non-English speaking countries and respondents with a lower level of education. Those respondents
TABLE 8

Accommodations for Working Aged People With Disability Who Were in the Labour Force

\begin{tabular}{lcc}
\hline & $\begin{array}{c}\text { Workplace accommodations } \\
\text { provided for people with } \\
\text { disability (15-64 years old) }\end{array}$ \\
\cline { 2 - 3 } & Frequency & Percentage ${ }^{*}$ \\
\hline A special support person to & 31,577 & 2.7 \\
$\quad$ assist/train on the job & 59,742 & 5.1 \\
$\begin{array}{l}\text { Provided special equipment } \\
\text { Modified buildings/fittings or } \\
\text { provided special/free } \\
\text { transport }\end{array}$ & 20,603 & 1.7 \\
$\begin{array}{l}\text { Provided training/retraining } \\
\text { Allocated different duties }\end{array}$ & 10,620 & 0.9 \\
Other & 29,337 & 2.5 \\
None of these arrangements & 15,015 & 1.3 \\
$\quad$ required or needed & 785,773 & 66.4 \\
Not applicable & & 23.7 \\
Total & 280515 & 104.2 \\
\hline Note: ${ }^{*}$ is more than 100\% because multiple responses were accepted.
\end{tabular}

needing employer-provided training had lower odds of being in the labour force. In contrast, those who were provided with a special support person at work were more likely to be in the labour force compared to those who did not receive or need such assistance. Other types

\section{TABLE 9}

Factors Influencing Labour Force Participation Adjusted for Age, Sex, Education, Country of Birth, and Workplace Accommodations

Odds Ratio $(95 \% \mathrm{Cl})$

\begin{tabular}{ll}
\hline Age $\left(60-64\right.$ years $\left.^{1}\right)$ & \\
15-29 years & $5.03(3.90-6.48)$ \\
$30-39$ years & $5.12(3.97-6.58)$ \\
40-49 years & $4.59(3.63-5.79)$ \\
$50-59$ years & $2.73(2.19-3.41)$ \\
Sex (female $\left.{ }^{1}\right)$ & \\
$\quad$ Male & $1.69(1.47-1.93)$ \\
Education (Year 12 not completed $\left.{ }^{1}\right)$ & \\
Postgraduate degree/ diploma & $5.81(3.92-8.60)$ \\
$\quad$ Bachelor degree & $4.35(3.36-5.63)$ \\
$\quad$ Diploma / certificate & $2.68(2.29-3.13)$ \\
$\quad$ Year 12 completed & $2.20(1.76-2.75)$ \\
Country of birth (non-English speaking $\left.{ }^{1}\right)$ & \\
$\quad$ English speaking & $2.09(1.70-2.56)$ \\
Workplace accommodations & \\
Provision of employer training & \\
Special support person at work &
\end{tabular}

Note: $\chi^{2}(13, N=4173)=731.155, p<.001$; Nagelkarke $R$ square $=$ $0.214, \mathrm{Cl}=$ Confidence Interval, ${ }^{1}$ indicates the reference category, ${ }^{2}$ reference category is those who did not receive or require this type of accommodation. 
of workplace accommodations did not significantly alter the odds of being in the labour force in this analysis.

\section{Discussion}

This research has confirmed previous studies on labour force participation of people with disability, whereby employment and earning disparities by disability status exist even when sociodemographic factors, such as level of education, are taken into account (Kidd et al., 2000; OECD, 2003). Differences in employment outcomes were observed by factors such as type and number of impairments, severity of disability, and presence of employment restrictions. These findings support previous assertions that disabled people are a heterogeneous group (Jones, 2011), with workplace participation and outcomes varying across a range of characteristics of disability (Hale et al., 1998; Oguzoglu, 2009; Wilkins, 2004). This raises an important point to consider when designing policies to increase labour force participation as it cannot be assumed that aggregated information is representative of work outcomes for the range of people reporting such disabilities.

Notably, the results of this study extend the literature in several ways. First, our data suggests that where the onus is placed on the employer to provide specific training for people with a disability, people with a disability reported lower odds of being in the labour force. Consistent with this outcome we also reported that less than a third of people in the labour force with employment restrictions received workplace accommodations from their employer. Based on this data, it seems reasonable to conclude that the workplace accommodation needs of a considerable proportion of people with disability are still not being met.

Several possibilities seem plausible in explaining this finding. It may be that that people with disability are self-selecting themselves into jobs wherein they avoid some employment restrictions and, therefore, circumvent having to ask employers to accommodate their needs. Such a strategy no doubt severely restricts the employment options of people with disability. The selfselection hypothesis may explain why employment outcomes are better for those with only one impairment, as their accommodation needs are likely to be less complex compared to those with multiple impairments the people who get jobs are those who participate in employment without making demands on their employers for accommodations. Those with multiple impairments may be more reliant on employer-provided workplace accommodations and, therefore, unable to join the labour force without their specific workplace needs being explicitly addressed by the employer. This hypothesis is also supported by the study by Hale and colleagues (1998), which indicated that those with severe disability are least likely to participate in the labour force $(29.9 \%$ participation rate), while those with com- paratively moderate disability may have a much higher labour force participation rate (81.6\%). This suggests, therefore, that there is a negative relationship between the extent to which accommodations are required in the workplace, and the rate of disability employment.

Second, it has been noted that there is very little open communication between employers and workers with disabilities about their condition (Gates, 1993). It is also possible that workplaces are simply unaware of the needs of many employees with disability. This may be in part explained by the reluctance of employees to request accommodations (Baldridge \& Veiga, 2001) due to fear of discrimination or stigma (Fesko, 2001; Frank \& Bellini, 2005). Bjelland and colleagues (2010) have suggested that in order for workplaces to understand the individual accommodation needs of their disabled workers, workers themselves need to be informed about their rights and supported in making requests for reasonable accommodations. We note particularly here our finding that where people with disability had access to an externally provided support person, who for example addressed specific training and accommodation needs, those people with disability were more likely to be in the labour force.

A further finding of the current study indicates that people with mental health issues experience the greatest degree of employment restrictions. This points to a general need for employers to be particularly cognisant of supporting workers experiencing ongoing mental health disabilities in accommodating their specific needs. The results of this study show that indeed a higher proportion of people with mental illness were provided accommodation by their employer. While this contrasts with earlier findings by Zwerling and colleagues (2003), this may be an effect of the range of conditions included in the category of mental health, with the Zwerling study including alcohol and drug abuse (for which high rates were reported) while the present study did not. The present results suggest that overall, persons with mental illness are more likely to require accommodation to enable them to participate in the labour force. More research into accommodation needs of people with mental illness is indicated, with only approximately one quarter of this subpopulation in the labour force at the time of the SDAC survey used in this study.

It is important to recognise that accommodations are not only valuable for their role in improving employment participation rates per se for those with disabilities (and the subsequent benefits to personal wellbeing), but also for their potential relationship with job satisfaction. The job in which one is employed must be considered satisfying by the worker in order to provide the benefits associated with employment (Graetz, 1993); in the presence of job strain, uncertainty and insecurity, the health benefits of employment may be negated (Broom et al., 2006). The presence of accommodations is likely 
to have an important positive influence on job satisfaction for those with disability, suggesting another mechanism by which the provision of workplace accommodations affects people with disability. Further investigation into this pathway of influence would provide important insights in the area of workplace accommodations for people with disability.

In interpreting these data, some limitations must be considered. First, employment outcomes are compared among people with and without disability, rather than with the general working age Australian labour force statistics; however, this approach was used by necessity in order to undertake detailed analysis by disability status and characteristics. Second, to compare the effects of different impairments and restrictions on labour force participation, a discrete classification scheme for disability was necessarily employed, rather than an exploration of disability and functioning on a continuum, as is the reality. While all such schemes have limitations, the International Classification of Functioning, Disability and Health (ICF) model used in this study attempts to overcome some of these limitations by using a biopsychosocial model of disability (World Health Organization \& United Nations Economic and Social Commission for Asia and the Pacific, 2008). As most persons have some impairment in a domain of functioning included in the ICF at least at some point in their lives, this broader approach taken by the ICF presents disability as a result of the interaction between health impairment with environmental and personal factors, rather than a solely body-based medical approach where disability is a special trait experienced by a minority of the population.

Studies such as these invariably raise a number of issues with regard to the kinds of conclusions one might draw from the analysis of cross-sectional data. Some concern exists because the sample for the study was randomly drawn from a cross-section of the community rather than a longitudinal study in which causality can be more readily assessed. There are also concerns about biases arising in the type of people who may respond to surveys such as these. For example, the labour force participation rate among people without disability in the SDAC survey is higher than that of the general Australian population and this may suggest that the population participating in this study is more advantaged and economically better off. If this were the case, it is likely that the employment and workplace accommodation outcomes for people with disability would be worse than those reported in this study. There might also be concerns raised regarding different definitions of disability that may affect comparability between studies. In response to such concerns, we first note the remarkably high level of consistency the results of this study have with studies in other countries, even where different methodologies were used. Second, the size of the sample in this study and its subsequent statistical power gives the reader confidence that it is highly unlikely that a significant counter-reality has been overlooked in this study with regards the experience of disability employment. Third, the latter point is strongly supported by the tightness of the confidence intervals reported, such that there is a high degree of commonality of experience among respondents on the issues of interest.

\section{Conclusion}

This study makes an important contribution to literature in the area of disability and employment, particularly workplace accommodations. It has been shown that people with disability continue to experience disadvantage compared to people without disability with respect to employment participation and earnings, and the degree of disparity differs according to a range of disability characteristics. While people with disability are motivated to participate in work to their full potential (Gates, 1993), it is clear that accommodation of individual employment needs for those with disabilities is still lacking. As has been identified elsewhere 'the optimal model of workplace training and support needs to be identified' (Hogan et al., 2002), and serious attempts made to implement these.

\section{Acknowledgements}

We are grateful for the support of Safe Work Australia (particularly Dr Jenny Job and Dr Peta Miller) in enabling us to extend our early work on this dataset to produce this new article. We would also like to thank Professor Dorothy Broom for her early comments on this article. Our dear friend and colleague, Christopher Newell, from the School of Medicine, University of Tasmania, Hobart, Australia, worked with us on earlier versions; Christopher sadly passed away before this article was completed. As a person with disability, Christopher experienced first hand many of the labour market issues discussed.

The authors report no conflicts of interest. The authors alone are responsible for the content and writing of this article. This study was conducted without financial support.

\section{References}

Australian Bureau of Statistics (ABS). (2005). Information paper: Basic confidentialised unit record file: Survey of Disability, Ageing and Carers. Canberra, Australia: Author.

Australian Bureau of Statistics (ABS). (2010). 6202.0 Labour Force, Australia. Canberra, Australia: Author.

Baldridge, D.C., \& Veiga, J.F. (2001). Toward a greater understanding of the willingness to request an accommodation: Can requesters' beliefs disable the Americans with Disabilities Act? The Academy of Management Review, 26(1), 85-99.

Bjelland, M.J., Bruyère, S.M., von Schrader, S., Houtenville, A.J., Ruiz-Quintanilla, A., \& Webber, D.A. (2010). Age and disability employment discrimination: Occupational rehabilitation 
implications. Journal of Occupational Rehabilitaiton, 20(4), 456471. doi: 10.1007/s10926-009-9194-z

Broom, D.H., D'Souza, R.M., Strazdins, L., Butterworth, P., Parslow, R., \& Rodgers, B. (2006). The lesser evil: Bad jobs or unemployment? A survey of mid-aged Australians. Social Science \& Medicine, 63, 575-586.

Butterfield, T.M., \& Ramseur, J.H. (2004). Research and case study findings in the area of workplace accommodations including provisions for assistive technology: A literature review. Technology and Disability, 16, 201-210.

Creed, P.A., \& Muller, J. (2006). Psychological distress in the labour market: Shame or deprivation? Australian Journal of Psychology, 58, 31-39.

Creed, P.A., Muller, J., \& Machin, M.A. (2001). The role of satisfaction with occupational status, neuroticism, financial strain and categories of experience in predicting mental health in the unemployed. Personality and Individual Differences, 30, 435447.

Ellingsen, K.L., \& Aas, R.W. (2009). Work participation after acquired brain injury: experiences of inhibiting and facilitating factors. The International Journal of Disability Management Research, 4(1), 1-11. doi: 10.1375/jdmr.4.1.1

Fabian, E.S., Waterworth, A., \& Ripke, B. (1993). Reasonable accommodations of workers with serious mental illness: Type, frequency, and associated outcomes. Psychosocial Rehabilitation Journal, 17(2), 163-172.

Fesko, S.L. (2001). Workplace experiences of individuals who are HIV+ and individuals with cancer. Rehabilitation Counseling Bulletin, 45(1), 2-11. doi: 10.1177/003435520104500101

Frank, J.J., \& Bellini, J. (2005). Barriers to the accommodation request process of the Americans with Disabilities Act. Journal of Rehabilitation, 71(2), 28-39.

Fryer, D. (1986). Employment deprivation and personal agency during unemployment: A critical discussion of Jahoda's explanation of the psychological effects of unemployment. Social Behaviour, $1,3-23$.

Gates, L.B. (1993). The role of the supervisor in successful adjustment to work with a disabling condition: Issues for disability policy and practice. Journal of Occupational Rehabilitation, 3, 179-190.

Graetz, B. (1993). Health consequences of employment and unemployment: Longitudinal evidence for young men and women. Social Science \& Medicine, 36(6), 715-724. doi: 10.1016/02779536(93)90032-y

Hale, T.W., Hayghe, H.V., \& McNeil, J.M. (1998). Persons with disability: Labour market activity, 1994. Monthly Labor Review 121, 3-12.

Hogan, A., Shipley, M., Strazdins, L., Purcell, A., \& Baker, E. (2011). Communication and behavioural disorders among children with hearing loss increases risk of mental health disorders. Australian and New Zealand Journal of Public Health, 35(4), 377-383. doi: 10.1111/j.1753-6405.2011.00744.x

Hogan, A., Stewart, M., \& Giles, E. (2002). It's a whole new ball game! Employment experiences of people with a cochlear implant. Cochlear Implants International, 3, 54-67.

Jahoda, M. (1982). Employment and unemployment: A social-psychological analysis. Cambridge, England: Cambridge University Press.

Jones, M.K. (2008). Disability and the labour market: A review of the empirical evidence. Journal of Economic Studies, 35, 405-424.
Jones, M.K. (2011). Disability, employment and earnings: An examination of heterogeneity. Applied Economics, 43(8), 1001-1017. doi: 10.1080/00036840802600053

Jones, M.K., \& Latreille, P.L. (2007). Disability, health, caring and the labour market: Evidence from the Welsh Health Survey. Sawnsea, United Kingdom: University of Wales.

Kidd, M.P., Sloane, P.J., \& Ferko, I. (2000). Disability and the labour market: an analysis of British males. Journal of Health Economics, 19, 961-981.

Lengnick-Hall, M.L., Gaunt, P.M., \& Kulkarni, M. (2008). Overlooked and underutilized: People with disabilties are an untapped human resource. Human Resource Management, 47, 255-273.

Meager, N., Dewson, S., Evans, C., Harper, H., McGeer, P., O'Regan, S., \& Tackey, N. (2002). Costs and benefits to service providers of making reasonable adjustments under part III of the Disability Discrimination Act. (DWP Research Report No. 169). Leeds, England: Corporate Document Services.

Menard, S.W. (2002). Applied logistic regression analysis. Thousand Oaks, CA: Sage.

Murphy, G.C., \& Athanasou, J. A. (1999). The effect of unemployment on mental health. Journal of Occupational and Organizational Psychology, 72, 83-99.

Murphy, G.C., \& Young, A.E. (2006). Employer-based facilitators of return to work following disabling injury. International Journal of Disability Management Research, 1(1), 125-134.

Office of Legislative Drafting and Publishing. (2006). Disability Discrimination Act 1992. Canberra, Australia: Australian Government.

Oguzoglu, U. (2009). Severity of work disability and work, Discussion Paper No. 4328 Discussion Paper Series. Bonn, Germany: Institute for the Study of Labor.

Organisation for Economic Co-operation and Development (OECD). (2003). Transforming disability into ability. Paris, France: Author.

Paul, K.I., Geithner, E., \& Moser, K. (2009). Latent deprivation among people who are employed, unemployed, or out of the labor force. The Journal of Psychology, 143, 477-491.

Roulstone, A., \& Warren, J. (2006). Applying a barriers approach to monitoring disabled people's employment: Implications for the Disability Discrimination Act 2005. Disability \& Society, 21(2), 115-131. doi: 10.1080/09687590500498036

Rumrill, P.D., Jr., Roessler, R. T., Battersby-Longden, J. C., \& Schuyler, B. R. (1998). Situational assessment of the accommodation needs of employees who are visually impaired. Journal of Visual Impairment \& Blindness, 92(1), 42-54.

Turner, J.B., \& Turner, R.J. (2004). Physical disability, unemployment, and mental health. Rehabilitation Psychology, 49, 241-249.

Wilkins, R. (2004). The effects of disability on labour force status in Australia. The Australian Economic Review, 37, 359-382.

World Health Organization, \& United Nations Economic and Social Commission for Asia and the Pacific. (2008). The ICF Framework: Training Manual of Disability Statistics (pp. 10-32). Bangkok, Thailand: Author.

Zwerling, C., Whitten, P.S., Sprince, N.L., Davis, C.S., Wallace, R.B., Blanck, P., \& Heeringa, S.G. (2003). Workplace accommodations for people with disabilities: National Health Interview Survey Disability Supplement, 1994-1995. Journal of Occupational and Environmental Medicine, 45, 517-525. 